\title{
TRADUÇÕES DE ALEKSANDR PÚCHKIN NO BRASIL
}

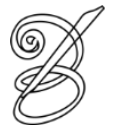 \\ Denise Bottmann ${ }^{\mathrm{i}}$ \\ Historiadora, tradutora, docente UNICAMP (1983-1998) \\ dbottmann@gmail.com
}

A grafia varia um pouco: Pushkin, Puskine, Puchkin, Puchkine, Puschkin. Atualmente, com a normatização da transposição fonética, consagrou-se o uso de Púchkin. Seguem-se as edições de sua obra em livro no país, excluídas as adaptações e quadrinizações.

Ao que tudo indica, o primeiro Púchkin entre nós saiu pela Livraria do Globo em 1933: A filha do capitão, em tradução de Paulo Corrêa Lopes (Figura 1).

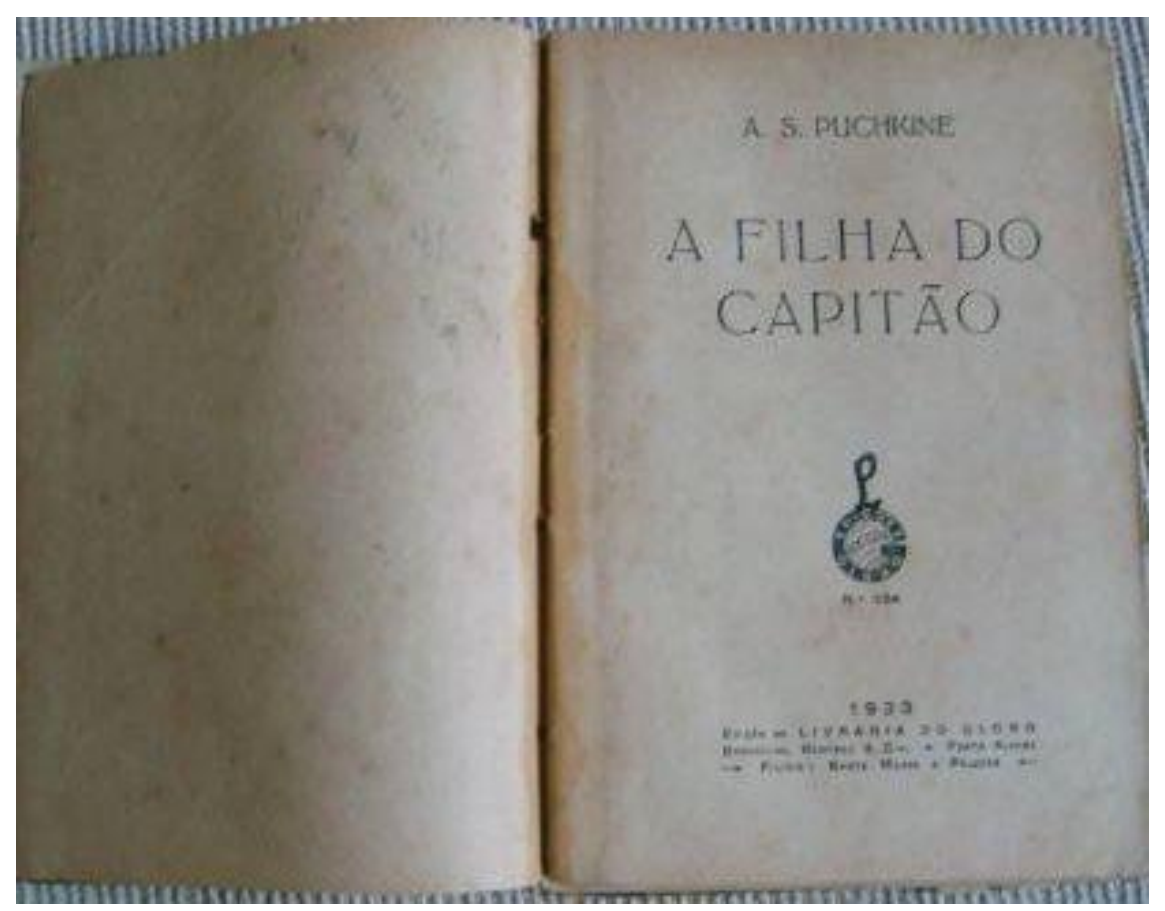

Figura 1

Depois, em 1935, a Civilização Brasileira (que então era um selo da Companhia Editora Nacional) publicou Águia negra, em sua Coleção Econômica SIP, vol. 32, sem crédito de tradução. 
Em 1937, sai pela Pongetti uma coletânea com Águia negra, A dama de espadas e Um tiro, em tradução de Cira Neri. Essa tradução de A dama de espadas é relançada pela Pongetti em 1961, numa coletânea chamada 3 novelas russas.

Em 1944, sai pela Companhia Editora Leitura a coletânea Os russos: antigos $e$ modernos, na coleção Livros do Mundo, com organização de Rubem Braga e supervisão de Graciliano Ramos. O volume traz dois contos de Púchkin, “A dama de espadas”, em tradução de Dias da Costa, e "O chefe de posta", em tradução de Aníbal Machado (Figura 2). Essa coletânea é reeditada nos meados dos anos 70 pela Ediouro (então Edições de Ouro), com o título de O livro de ouro dos contos russos, e agora em 2004 com o título de Contos russos: os clássicos.

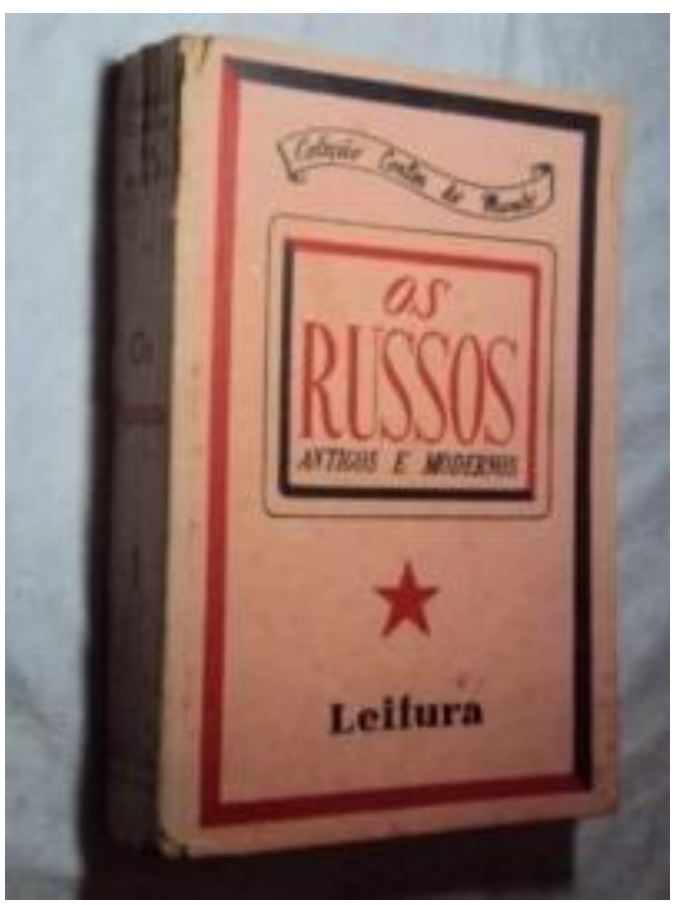

Figura 2

Ainda em 1944, é lançada a antologia Os colossos do conto da velha e da nova Rússia, pela Editora Mundo Latino, com "A tempestade de neve”, em tradução de Edison Carneiro.

Também em 1944, a Vecchi lança Os mais belos contos russos dos mais famosos autores, $1^{\text {a }}$. Série, trazendo de Púchkin “A camponesa disfarçada”, em tradução de Manuel R. da Silva. Em 1945, a Vecchi lança a segunda série de Os mais belos contos russos dos mais famosos autores, com “Um disparo memorável”, em tradução de Carlos Casanova. 
No mesmo ano, Álvaro Moreyra lança sua tradução d'A dama de espadas pela Brasilia aeterna. Aliás, essa tradução fora publicada em 1944, com tiragem especial para a Confraria de Bibliófilos Brasileiros Cattleya Alba, numa edição numerada de luxo, com capa de seda e ilustrações de Martha Pawlowna Schidrowitz feitas à mão (Figura 3). Note-se de passagem o triste destino que terá essa tradução sessenta anos depois: foi apropriada pela Martin Claret, que a partir de 2006 passou a se arvorar em detentora de seus direitos autorais.

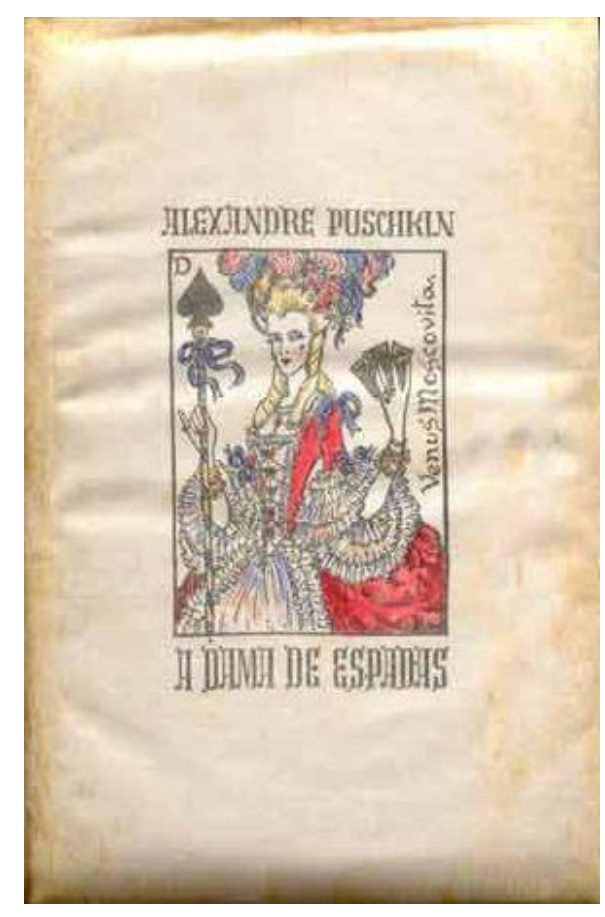

Figura 3

Em 1949, em sua coleção Os Maiores Êxitos das Telas, a Vecchi publica dois volumes em tradução de Boris Solomonov (pseudônimo semipatronímico que Boris Schnaiderman adotava em suas traduções daquela época). São eles A filha do capitão e Águia negra. Este último contém “Águia negra”, "O negro de Pedro, o Grande”, "O encarregado da estação" e “Kirdjali". "O negro de Pedro, o Grande" será reeditado pela Difel em 1962 (Figura 4). Os quatro contos da coletânea serão reeditados pela 34 em 1999, "O encarregado da estação" renomeado como "O chefe da estação" e "Águia negra" como "Dubróvski”". Quanto a essa tradução d'A filha do capitão,será reeditada inúmeras vezes ao longo das décadas. Com o encerramento da Vecchi, seu catálogo passou para a Tecnoprint (futura Ediouro). Acrescida de prefácio de Otto Maria Carpeaux, sai na década de 1970 pela Edições de Ouro, em sua coleção Universidade, e em 1996 pela coleção Clássicos de Bolso da Ediouro. 


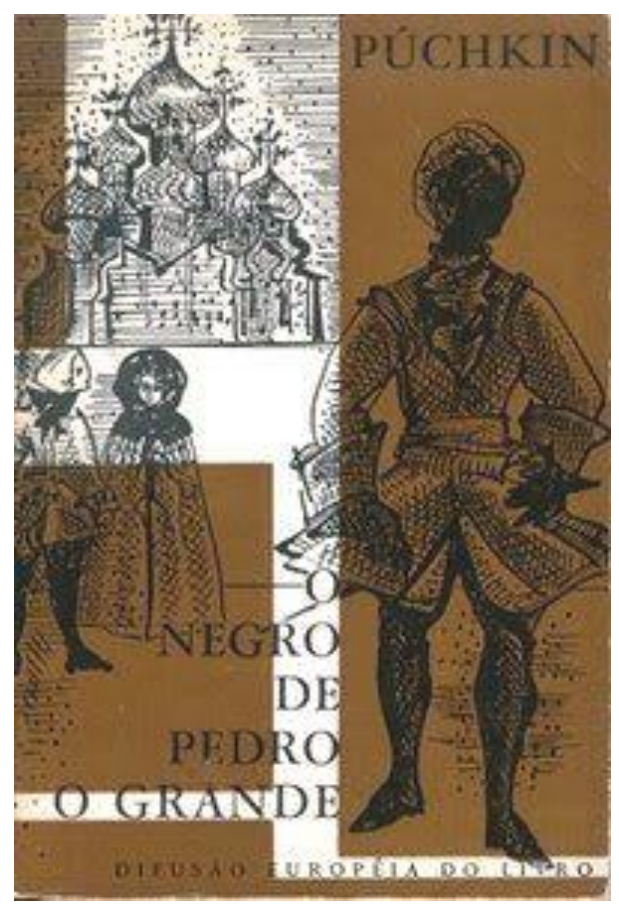

Figura 4

244 Em 1951, temos "O tiro" no segundo volume de Mar de histórias, em organização e tradução de Aurélio Buarque de Hollanda e Paulo Rónai (Figura 5).

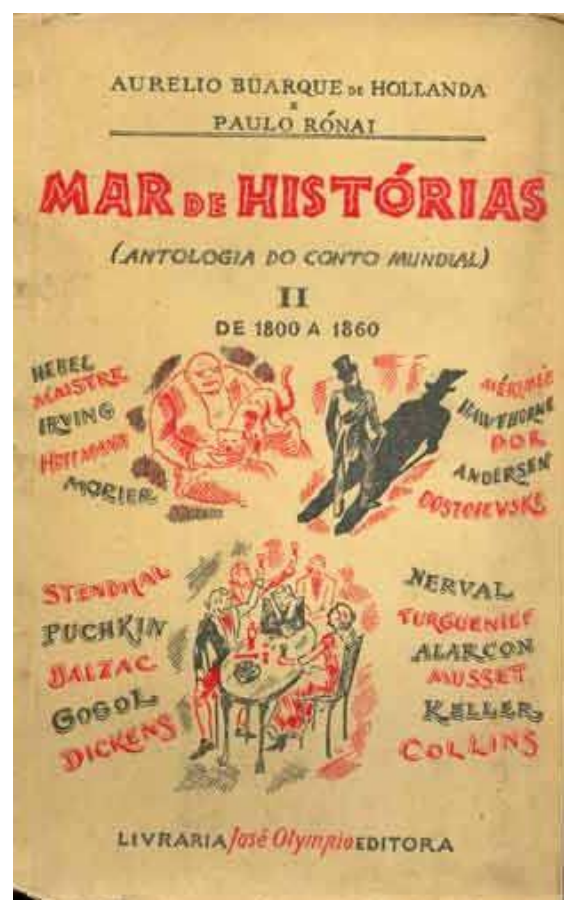

Figura 5 
Em 1957, a Cultrix lança "O turbilhão de neve" na antologia Maravilhas do conto russo, com seleção a cargo de um implausível "Serge Ivanovitch", sem crédito de tradução.

Em 1961, sai o primeiro volume da vasta Antologia do conto russo em nove volumes, pela Editora Lux, trazendo os seguintes contos de Púchkin: "A filha do capitão", em tradução de Leontina Vassilieva e Renard Perez (relançada em 1963 pela BUP, em volume único); "Nevasca" e "Moça camponesa", ambos em tradução de Natália Filipov e Renard Perezii (Figura 6).

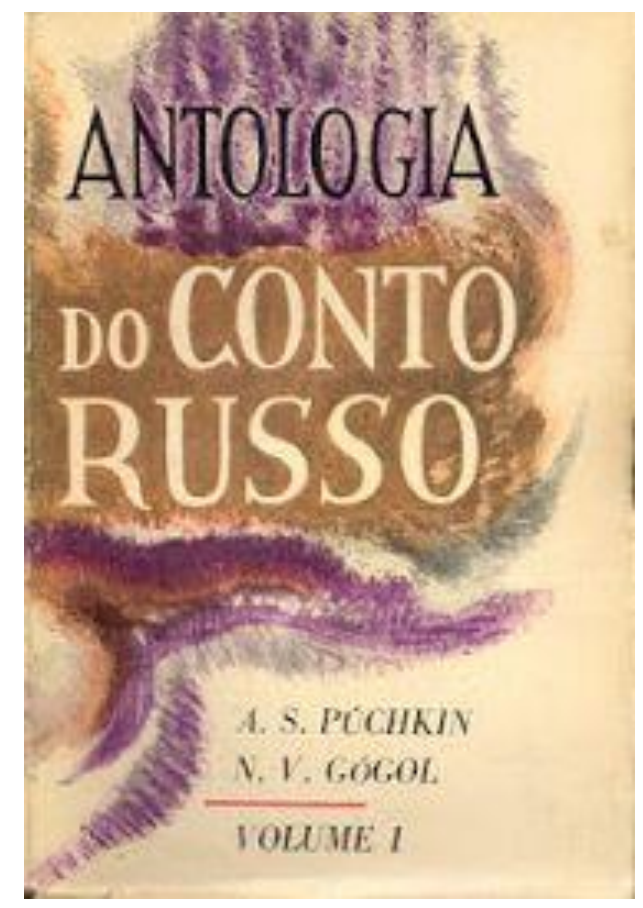

Em 1962, sai "O tiro" na antologia Contos russos organizada por Jacob Penteado, na coleção Primores do Conto Universal, pela Edigraf, sem créditos de tradução.

Boris Schnaiderman, em “Caleidoscópio de tradutor", menciona uma antologia que ele teria montado e publicado em 1962, trazendo sua tradução d' “O empresário fúnebre”, depois reeditada em 1981 como "O fabricante de ataúdes" e em 1999 como "O fazedor de caixões". Não consegui localizar a antologia de 1962 com o referido conto.

Em 1964, saem os Contos de Belkin, pela Brasiliense, em tradução de Eduardo Sucupira Filho. 
Ainda em 1964, sai "O fabricante de ataúdes" na antologia Obras-primas do conto russo, pela Livraria Martins, com introdução, seleção e notas de Homero Silveira. Não consta o nome do tradutor, mas, pelo texto disponível, parece de lavra lusitana.

Em 1968, "Mozart e Salieri” é publicado em tradução de Tatiana Belinky em Teatro da Juventude, vol. 4, n. 18, pela Comissão Estadual de Teatro de São Paulo.

Em 1980, a Otto Pierre lança Contos breves, com: "A casinha solitária da ilha Basílio", “A fidalga camponesa”, “Azar no jogo”, "O desafio”, “O bandido Dubrovsky”, "O czar Saltan, o valoroso herói Gvidon Saltanovich e a formosa princesa Cisne", "Conto da czarevna morta e dos sete guerreiros" e "O prisioneiro do Cáucaso". Como a Otto Pierre publicava muitas coisas de Portugal, não duvido que se trate de tradução lusitana.

Ainda em 1980, sai pela Perspectiva a tradução de Helena S. Nazário de A filha do capitão.

Em 1981, sai A dama de espadas em tradução de Boris Schnaiderman, pela Max Limonad.

Em 1988, a Paulinas publica $O$ pope avarento, bem como o conto "Nevasca" numa 246 antologia de nome Salada russa, ambos em tradução de Tatiana Belinky.

Ainda em 1988, a Editora Formar publica uma coleção de três volumes, chamada "Mundo Infantil". No vol. 3 está incluído o conto "O tzar saltão". Ignoro o nome do tradutor.

Em 1992, sai um volume de Poesias escolhidas, com seleção e tradução de José Casado, pela Nova Fronteira.

Em 1999, pela 34, sai a coletânea A dama de espadas - prosa e poemas, em tradução de Boris Schnaiderman (prosa e poesia) e Nelson Ascher (poesia).Traz: "O negro de Pedro, o Grande","Dubróvski”, “O chefe da estação","Kirdjali” (vide 1945, Vecchi), “O tiro”; “O fazedor de caixões" e "A dama de espadas" na parte em prosa. Os poemas são "O demônio", "O semeador", “A uva", "O prosador e o poeta", "Para ***”, “Alexandre I", "Nicolau I", "Para Viázemski”,“O profeta”,“Árion”,"Mensagem à Sibéria”, "Dom inútil...”, “Corvos”, “O antchar","O cavaleiro pobre" e "Amei-te...".

Em 2003, a Nova Alexandria lança os Contos de Belkin, com "O tiro", "A nevasca", "O agente funerário", "O chefe da posta" e "A sinhazinha camponesa", agora em tradução de Klara Gouriánova.

Em 2004, sai uma antologia de Contos russos eternos, pela BomTexto, organizada por Maria do Carmo S. Campos e com tradução de José Augusto Carvalho. Não sei qual é o conto de Púchkin incluído na coletânea. 
Ainda em 2004, sai o Caderno de literatura e cultura russa dedicado a Púchkin, pela Ateliê/ USP, com um dossiê que inclui a tradução de excertos de Evguiéni Oniéguin, "Romance em cartas", "Sobre poesia clássica e romântica" e "Esboços de um prefácio a Boris Godunov".

Em 2006, a Globo lança Pequenas tragédias em tradução de Irineu Franco Perpétuo. São elas: "O cavaleiro avarento", "Mozart e Salieri”, "O convidado de pedra" e "O festim nos tempos da peste".

Ainda em 2006, saem A filha do capitão / A dama de espadas pela Martin Claret, com uma inverossímil alegação de copyright sobre as traduções de Álvaro Moreyrae .

Em 2007, sai Boris Godunov em tradução, notas e posfácio de Irineu Franco Perpétuo, pela Globo.

Em 2010, pela Hedra, temos Noites egípcias e outros contos traduzidos por Cecília Rosas. Além de três dos contos de Belkin, "Do editor", "A nevasca" e "A senhorita camponesa", a seleta traz "A casinha solitária na ilha de Vassili", "História do povoado de Goriúkhino" e as "Noites egípcias" do título.

Em 2010, sai Eugênio Onêguin em tradução de Dário Moreira de Castro Alves, pela Record. Essa tradução foi inicialmente publicada em 2008 em Moscou, pelo grupo editorial Asbooka-Atticus, em edição bilíngue.

Em 2011, sai "Viagem a Arzrum" na Nova antologia do conto russo - 1792-1998, pela editora 34, organizada por Bruno Gomide, em tradução de Cecília Rosas.

Em 2012, sai a coletânea de Pequenas tragédias pela Martin Claret, em tradução de Oleg Almeida, com "O cavaleiro avaro", "Mozart e Salieri”, "O convidado de pedra (Dom Juan)" e "O festim em tempos da peste".

Em 2013, temos $O$ conto maravilhoso do tsar Saltan, em tradução de Cecilia Rosas, pela Cosac Naify.

RECEBIDO EM 21/06/2014

ACEITO EM 28/06/2014

\footnotetext{
i Currículo lattes - Denise Guimarães Bottman. Disponível em: http://lattes.cnpq.br/4979718236781288.

ii Agradeço a Carlos Baboni pelas referências dos contos e respectivos tradutores.
} 